American Journal of Applied Sciences 4 (7): 417-425, 2007

ISSN 1546-9239

(C) 2007 Science Publications

\title{
Feedback of the Input Voltage in FDTC Control Using a Three-Level NPC-VSI
}

\author{
${ }^{1}$ R. Zaimeddine and ${ }^{2}$ E.M. Berkouk \\ ${ }^{1}$ Department of Electrical Engineering, 'Signals and Systems' Research laboratory \\ University of M'hamed Bougara, Boumerdes, Algeria \\ ${ }^{2}$ Process Control Laboratory, National Polytechnic School, Algiers, Algeria \\ 10 Avenue Pasteur, Hassan Badi, BP. 182, El-Harrach
}

\begin{abstract}
A new control structure for sensorless induction machine dedicated to electrical drives using a three-level voltage source inverter VSI-NPC is completely analysed. The amplitude and the rotating velocity of the flux vector could be controlled freely. Both fast torque and optimal switching logic could be achieved; the selection is based on the value of the stator flux and the torque. A novel DTC scheme of induction motors is proposed in order to develop a suitable dynamic. We proposed a DTC approach based in fuzzy logic, in witch the response of torque and flux is enhanced trough optimal switching strategies and torque ripple minimisation is achieved. However, the middle point voltage of the input DC voltages of the three-level NPC voltage source inverter presented serious problems caused by a fluctuation of the $\mathrm{DC}$ voltage sources $\mathrm{U}_{\mathrm{CU}}, \mathrm{U}_{\mathrm{CL}}$. As consequence to these problems, we obtained an output voltage of the inverter, which is asymmetric and with an average value different from zero. We presented one solution to minimise this fluctuation. This solution used a feedback to regulate the input voltages of a three-level inverter VSI NPC. A scheme of a fuzzy direct torque control "FDTC" with complete cascade is simulated for an induction motor. The results obtained indicate superior performance over the FOC one without need to any mechanical sensor.
\end{abstract}

Keywords: Direct torque control, fuzzy control, field oriented control, flux estimators, induction motor, multi-level inverter, neural-point clamped, sensorless vector control, switching strategy optimisation, fast torque response

\section{INTRODUCTION}

The rapid development of the capacity and switching frequency of the power semiconductor devices and the continuous advance of the power electronics technology have made many changes in static power converter systems and industrial motor drive areas. The conventional GTO inverters have limitation of their dc-link voltage. Hence, the series connections of the existing GTO thyristors have been essential in realizing high voltage and large capacity inverter configurations with the dc-link voltage ${ }^{[1]}$. The vector control of induction motor drive has made it possible to be used in applications requiring fast torque control such as traction ${ }^{[2]}$. In a perfect field oriented control, the decoupling characteristics of the flux and torque are affected highly by the parameter variation in the machine.

This paper describes a control scheme for direct torque and flux control of induction machines fed by a three-level inverter using a switching table. In this method, the output voltage is selected and applied sequentially to the machine through a look-up table so that the flux is kept constant and the torque is controlled by the rotating speed of the stator flux. The direct torque control (DTC) is one of the actively researched control scheme which is based on the decoupled control of flux and torque providing a very quick and robust response with a simple control construction in ac drives $^{[3,4]}$.

The suggested technique is based on applying to the inverter the selected active states just enough time to achieve the torque and flux references values.

We propose a FDTC system for high voltage and high power applications. This structure lets to absorb, in network, sinusoidal currents with unity power factor. It constitutes by two-level PWM rectifier, feedback linear control using IP regulator, three-level NPC-VSI, induction motor controlled by FDTC strategy.

Three-level inverter topology: Fig. 1 shows the schematic diagram of neutral point clamped (NPC)

Corresponding Author: R. Zaimeddine, Department of Electrical Engineering, 'Signals and Systems' Research laboratory University of M'hamed Bougara, Boumerdes, Algeria 


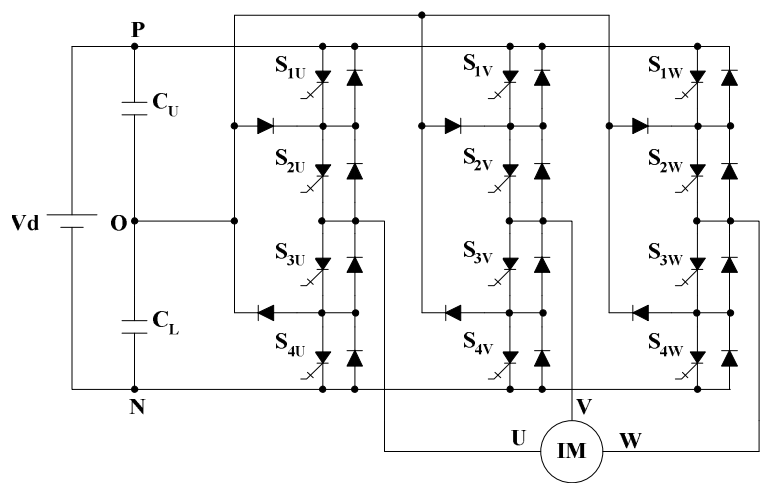

Fig. 1: Schematic diagram of a three-level GTO inverter

three-level VSI. Each phase of this inverter consists of two clamping diodes, four GTO thyristors and four freewheeling diodes. Table 1 shows the switching states of this inverter. Since three kinds of switching states exist in each phase, a three level inverter has 27 switching states.

Table 1: Switching states of a three-level inverter

\begin{tabular}{llllll}
\hline Switching states & $\mathrm{S}_{1}$ & $\mathrm{~S}_{2}$ & $\mathrm{~S}_{3}$ & $\mathrm{~S}_{4}$ & $\mathrm{~V}_{\mathrm{N}}$ \\
\hline $\mathrm{P}$ & $\mathrm{ON}$ & $\mathrm{ON}$ & $\mathrm{OFF}$ & $\mathrm{OFF}$ & $\mathrm{V}_{\mathrm{d}}$ \\
$\mathrm{O}$ & OFF & ON & ON & OFF & $\mathrm{V}_{\mathrm{d}} / 2$ \\
$\mathrm{~N}$ & OFF & OFF & ON & ON & 0 \\
\hline
\end{tabular}

A two-level inverter is only able to produce six non-zero voltage vectors and two zero vectors ${ }^{[2]}$. The representation of the space voltage vectors of a threelevel inverter for all switching states forming a twolayer hexagon centred at the origin of the $(d, q)$ plane and a zero voltage vector at the origin of the plane, as depicted in Fig. 2. According to the magnitude of the voltage vectors, we divide them into four groups : the zero voltage vectors $\left(\mathrm{V}_{0}\right)$, the small voltage vectors $\left(\mathrm{V}_{1}\right.$ $\left., \mathrm{V}_{4}, \mathrm{~V}_{7}, \mathrm{~V}_{10}, \mathrm{~V}_{13}, \mathrm{~V}_{16}\right)$, the middle voltage vectors $\left(\mathrm{V}_{3}, \mathrm{~V}_{6}, \mathrm{~V}_{9}, \mathrm{~V}_{12}, \mathrm{~V}_{15}, \mathrm{~V}_{18}\right)$, the large voltage vectors $\left(\mathrm{V}_{2}, \mathrm{~V}_{5}, \mathrm{~V}_{8}, \mathrm{~V}_{11}, \mathrm{~V}_{14}, \mathrm{~V}_{17}\right)$.

The zero voltage vector (ZVV) has three switching states, the small voltage vector (SVV) has two and both the middle voltage vector (MVV) and the large voltage vector (LVV) have only one ${ }^{[1]}$.

Induction machine: Torque control of an induction motor can be achieved on the basis of its model developed in a two axis $(\mathrm{d}, \mathrm{q})$ reference frame stationary with the stator winding. In this reference frame and with conventional notations, the electrical mode is described by the following equations:

$$
\begin{aligned}
& \frac{d i_{S d}}{d t}=\frac{1}{\sigma T_{r} L_{S}} \varphi_{s d}+\frac{p \Omega}{\sigma L_{S}} \varphi_{s q}-\frac{1}{\sigma}\left(\frac{1}{T_{r}}+\frac{1}{T_{S}}\right) i_{s d}-p \Omega i_{S q} \\
& +\frac{1}{\sigma L_{s}} V_{s d}
\end{aligned}
$$

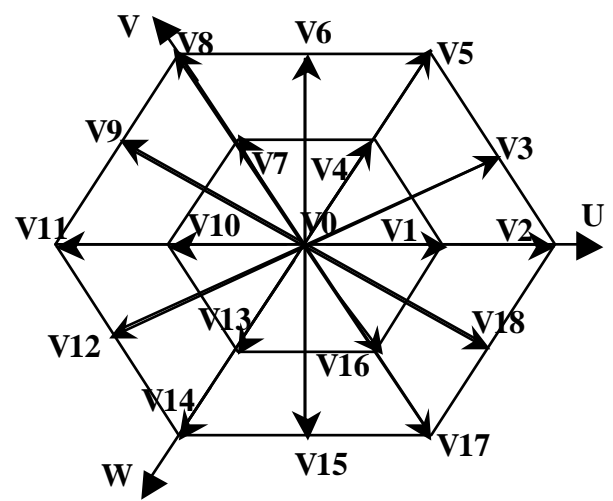

Fig. 2: Space voltage vectors of a three-level inverter

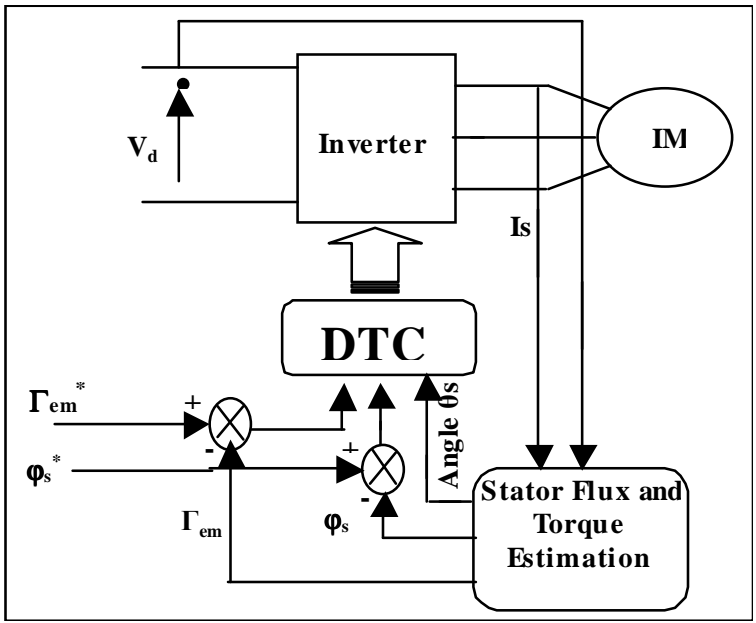

Fig. 3: Block diagram of direct torque control

$\frac{d i_{s q}}{d t}=-\frac{p \Omega}{\sigma L_{S}} \varphi_{s d}+\frac{1}{\sigma T_{r} L_{S}} \varphi_{s q}-\frac{1}{\sigma}\left(\frac{1}{T_{r}}+\frac{1}{T_{S}}\right) i_{s q}+p \Omega i_{s d}$

$+\frac{1}{\sigma L_{S}} V_{s q}$

$\frac{d \varphi_{s d}}{d t}=V_{s d}-R_{S} i_{S d}$

$\frac{d \varphi_{s q}}{d t}=V_{s q}-R_{s i} i q$

The mechanical mode associated to the rotor motion is described by:

$J \frac{d \Omega}{d t}=\Gamma_{e m}-\Gamma_{L}(\Omega)$

$\Gamma_{L}(\Omega)$ and $\Gamma_{e m}$ are respectively the load torque and the electromagnetic torque developed by the machine.

Basic dtc principles: Fig. 3 shows a block diagram of the DTC scheme developed by I. Takahashi ${ }^{[2]}$. The reference values of flux, $\varphi_{\mathrm{s}}{ }^{*}$ and torque, $\Gamma_{\mathrm{em}}{ }^{*}$, are 
compared to their actual values and the resultant errors are fed into a two level comparator of flux and torque. The stator flux angle, $\theta_{\mathrm{s}}$ is calculated by:

$$
\theta_{s}=\arctan \frac{\varphi_{s q}}{\varphi_{s d}}
$$

and quantified into 12 levels depending on which sector the flux vector falls into. Different switching strategies can be employed to control the torque according to whether the flux has to be reduced or increased.

Each strategy affects the drive behavior in terms of torque and current ripple, switching frequency and two or four-quadrant operation capability. Assuming the voltage drop $\left(R_{s} . i_{s}\right)$ small, the head of the stator flux $\varphi_{S}$ moves in the direction of stator voltage $V_{s}$ at a speed proportional to the magnitude of $\mathrm{V}_{\mathrm{s}}$ according to

$\Delta \varphi_{\mathrm{S}}=\mathrm{V}_{\mathrm{s}} \mathrm{T}_{\mathrm{e}}$

The switching configuration is made step by step, in order to maintain the stator flux and torque within limits of two hysteresis bands. Where $T_{e}$ is the period in which the voltage vector is applied to stator winding. Selecting step by step the voltage vector appropriately, it is then possible to drive $\varphi_{\mathrm{s}}$ along a prefixed track curve.

Assuming the stator flux vector lying in the $\mathrm{k}$-th sector $(\mathrm{k}=1,2,3 \ldots, 12)$ of the $(\mathrm{d}, \mathrm{q})$ plane, in the case of three-level inverter, to improve the dynamic performance of DTC at low speed and to allow fourquadrant operation, it is necessary to involve the voltage vectors $\mathrm{V}_{\mathrm{K}-1}$ and $\mathrm{V}_{\mathrm{K}-2}$ in torque and flux control. In the following, $\mathrm{V}_{\mathrm{K}-1}$ and $\mathrm{V}_{\mathrm{K}-2}$ will be denoted "backward" voltage vectors in opposition to "forward" voltage vectors used to denote $\mathrm{V}_{\mathrm{K}+1}$ and $\mathrm{V}_{\mathrm{K}+2}$. A simple strategy which makes use of these voltage vectors is shown in Table 2.

Table 2: Selection strategy for four-quadrant operation

\begin{tabular}{lll}
\hline & $\Gamma_{\mathrm{em}} \uparrow$ & $\Gamma_{\mathrm{em}} \downarrow$ \\
\hline$\varphi_{\mathrm{s}} \uparrow$ & $\mathrm{V}_{\mathrm{K}+1}$ & $\mathrm{~V}_{\mathrm{K}-1}$ \\
$\varphi_{\mathrm{s}} \downarrow$ & $\mathrm{V}_{\mathrm{K}+2}$ & $\mathrm{~V}_{\mathrm{K}-2}$ \\
\hline
\end{tabular}

For steady operating conditions, equations (15) describing the electromagnetic torque can be transformed to a sinus function:

$\Gamma_{\text {elmo }}=\Gamma_{\max o} \cdot \sin 2 \gamma_{o}$

$\Gamma \max o$ and $\gamma_{o}$ are respectively torque and the phase shift angle between stator and rotor flux vectors.

$\Gamma_{\max o}=p \cdot \frac{1-\sigma}{2 \cdot \sigma \cdot L_{s}} \cdot \varphi_{s o}^{2} ; \gamma_{o}=\theta_{s o}-\theta_{\text {ro }}$

Equations (8) and (9) are established with the assumption that stator flux and rotor closed values in steady state. For disturbed states, the stator flux angle $\theta_{\mathrm{s}}$ has in practice a fast dynamic mode as compared to the rotor flux angle $\theta_{\mathrm{r}}$. If these two assumptions are valid the effect of stator vector voltage on the machine torque can be expressed by the first order Taylor expansion as below:

$$
\Delta \Gamma_{e l m} \approx K_{\varphi} \cdot \Delta \varphi_{s}+K_{\theta} \cdot \Delta \theta_{s}
$$

The sensitivity coefficients $\mathrm{K} \varphi$ and $\mathrm{K} \theta$ are defined by:

$$
\left\{\begin{array}{l}
K_{\varphi}=\frac{d \Gamma_{e l m}}{d \varphi_{s}}=\frac{2}{\varphi_{s o}} \cdot \Gamma_{\text {elmo }} \\
K_{\theta}=\frac{d \Gamma_{\text {elm }}}{d \theta_{s}}=2 \cdot \Gamma_{\max o} \cdot \cos 2 \gamma_{o}
\end{array}\right.
$$

Using equations (10), (11) and (14) leads to:

$$
\begin{array}{rl}
\Delta \Gamma_{\text {elm }}=2 & 2 \cdot \frac{V_{s} \cdot T_{e}}{\varphi_{\text {so }}} \cdot \Gamma_{\text {elmo }} \cdot \cos \left(\theta_{v}-\theta_{\text {so }}\right) \\
& +\frac{2 \cdot V_{s} \cdot T_{e}}{\varphi_{\text {so }}} \cdot \sqrt{\Gamma_{\max o}^{2}-\Gamma_{\text {elmo }}^{2}} \cdot \sin \left(\theta_{v}-\theta_{\text {so }}\right)
\end{array}
$$

This shows the feasibility torque control by a well selected vectors voltage $\overline{V s}^{[5]}$. According to this strategy, the stator flux vector is required to rotate in both positive and negative directions. By this, even at very low shaft speed, large negative values of rotor angular frequency can be achieved, which are required when the torque is to be decreased very fast. Furthermore, the selection strategy represented in Table 2 allows good flux control to be obtained even in the low speed range. However, the high dynamic performance which can be obtained using voltage vectors having large components tangential to the stator vector locus implies very high switching frequency.

Stator flux and torque estimation: Basically, DTC schemes require the estimation of the stator flux and torque. The stator flux evaluation can be carried out by different techniques depending on whether the rotor angular speed (position) is measured or not. For sensorless application, the "voltage model" is usually employed $^{[6]}$. The stator flux can be evaluated by integrating from the stator voltage equation.

$\varphi_{S}(t)=\int\left(V s-R_{S} I_{S}\right) d t$

This method is very simple requiring the knowledge of the stator resistance only. The effect of an error in Rs is usually quite negligible at high excitation frequency but becomes more serious as the frequency approaches zero ${ }^{[6]}$.

Fig. 4 shows the deviation obtained at the end of the switching period Te, which can be approximated by the first order Taylor Series as below.

$$
\begin{aligned}
& \Delta \varphi_{s} \approx V_{s} \cdot T_{e} \cdot \cos \left(\theta_{v}-\theta_{s}\right) \\
& \Delta \theta_{s} \approx T_{e} \cdot \frac{V_{s} \cdot \sin \left(\theta_{v}-\theta_{s}\right)}{\varphi_{s o}}
\end{aligned}
$$




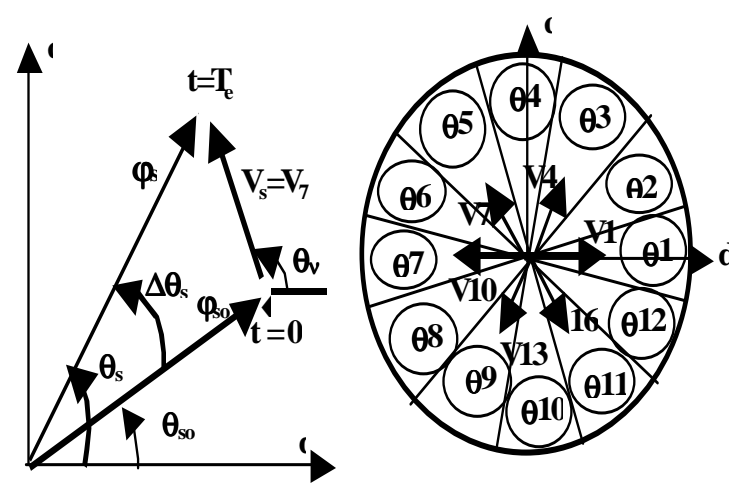

Fig. 4: Flux deviation

Considering the combination of states of switching functions $S_{u}, S_{v}, S_{w}$. Figure 4 shows the adequate voltage vector selection we can increase or decrease the stator flux amplitude and phase to obtain the required performances. The electric torque is estimated from the flux and current as ${ }^{[2]}$ :

$\Gamma_{e m}=p\left(i_{s q} \varphi_{s d}-i_{s d} \varphi_{s q}\right)$

Switching strategy for fuzzy controller: A switching Table is used to select the best output voltage depending on the position of the stator flux and desired action on the torque and stator flux. The flux position in the (d, q) plane is quantified in twelve sectors. Alternative tables exist for specific operation mode. The switching table for the case of a two-level inverter developed by I. Takahashi ${ }^{[2]}$, permits easily to expand the optimal vector selection to include the larger number of voltage vectors produced by three-level inverter. The appropriate vector voltage is selected in the order to reduce the number of commutation and the level of steady-state ripple.

For flux control, let the variable $E_{\varphi}\left(E_{\varphi}=\varphi_{s}{ }^{*}-\varphi_{s}\right)$ located in one of the three regions fixed by the contraints : $E_{\varphi}<E_{\varphi \min }, E_{\varphi \min } \leq E_{\varphi} \leq E_{\varphi \max }, E_{\varphi}>E_{\varphi \max }$. The switable flux level is then bounded by $\mathrm{E}_{\varphi \text { min }}$ and $\mathrm{E}_{\text {qmax }}$. The flux control is made by two-level hysteresis comparator. Three regions for flux location are noted, flux as in fuzzy control schemes, by $\mathrm{E}_{\varphi n}$ (negative), $\mathrm{E}_{\varphi z}$ (zero) and $\mathrm{E}_{\varphi p}$ (positive).

A high level performance torque control is required. To improve the torque control, let the diferrence $\left(\mathrm{E}_{\Gamma}=\Gamma_{\mathrm{em}}{ }^{*}-\Gamma_{\mathrm{e}}\right)$ belong to one of the five regions defined by the contraints :

$\mathrm{E}_{\Gamma}<\mathrm{E}_{\Gamma \min 2}, \mathrm{E}_{\Gamma \min 2} \leq \mathrm{E}_{\Gamma} \leq \mathrm{E}_{\Gamma \min 1}, \mathrm{E}_{\Gamma \min 1} \leq \mathrm{E}_{\Gamma} \leq \mathrm{E}_{\Gamma \max 1}$, $\mathrm{E}_{\Gamma \max 1} \leq \mathrm{E}_{\Gamma} \leq \mathrm{E}_{\Gamma \max 2}$ and $\mathrm{E}_{\Gamma \max 2}<\mathrm{E}_{\Gamma}$.

The five regions defined for torque location are also noted, as in fuzzy control schemes, by $\mathrm{E}_{\Gamma \mathrm{nl}}$

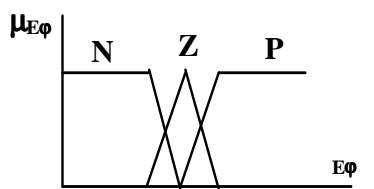

(a)

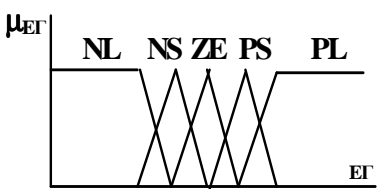

(b)

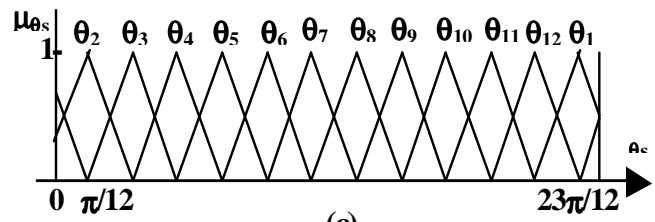

(c)

Fig. 5: Membership distribution of fuzzy variables

(negative large), $\mathrm{E}_{\Gamma \mathrm{ns}}$ (negative small), $\mathrm{E}_{\Gamma \mathrm{z}}$ (zero), $\mathrm{E}_{\Gamma \mathrm{ps}}$ (positve small), $\mathrm{E}_{\Gamma \mathrm{pl}}$ (positve large). The torque is then controlled by an hysteresis comparator built with two lower bounds and two upper bounds. The conventional DTC has been studied, ${ }^{[7,8]}$.

The fuzzy controller: Flux error " $\mathrm{E}_{\varphi}$ " torque error " $\mathrm{E}_{\Gamma}$ " and flux position " $\theta$ " are used as inputs to the fuzzy controller, the inverter switchnig state " $n$ " is the output of the controller. The three input variables are divided into their fuzzy segments. The membre of fuzzy segments are chosen to have maximum control with a minimum number of rules. The grade of member distribution of input variables into their fuzzy segments is schown in Fig. 5. The control rule is described by the input variables $\mathrm{E}_{\varphi}, \mathrm{E}_{\Gamma}$ and $\theta_{\mathrm{s}}$ and the control variable $\mathrm{n}$ as:

$\mathrm{R}_{\mathrm{i}}$ : if $\mathrm{E}_{\varphi}$ is $\mathrm{A}_{\mathrm{i}}, \mathrm{E}_{\Gamma}$ is $\mathrm{B}_{\mathrm{i}}$ and $\theta$ is $\mathrm{C}_{\mathrm{i}}$ than $\mathrm{n}$ is $\mathrm{N}_{\mathrm{i}}$

Switching strategy for fuzzy controller: The rules are formulated using the vector diagram for direct torque control and flux control of induction machine showed Fig. 4. The switching strategy in the order of the sector $\theta \mathrm{s}$, is illustrated by each table. The flux and torque control by vector voltage has in nature a desecrate behavior. In fact, we can easily verify that the same vector could be adequate for a set of value of $\theta_{\mathrm{s}}$. The number of sectors should be as large as possible to have an adequate decision. For this reason, we propose a new approach for direct torque control using a three-level inverter based on twelve regular sectors noted by $\theta_{1}$ to $\theta_{12}$. A switching table is used to select the best output voltage depending on the position of the stator flux and desired action on the torque and stator flux. It is possible to expand the optimal vector selection to include the larger number of regular sectors and fuzzy segments of input variables. 


\begin{tabular}{|c|c|c|c|c|c|c|c|}
\hline \multicolumn{4}{|c|}{$\theta 1$} & \multicolumn{4}{|c|}{$\boldsymbol{\theta} 2$} \\
\hline $\mathbf{E}_{\Gamma}$ & $\overline{\mathbf{P}}$ & $\overline{\mathbf{Z}}$ & $\mathbf{N}$ & & $\overline{\mathbf{P}}$ & $\mathbf{Z}$ & $\mathbf{N}$ \\
\hline PL & 5 & 4 & 8 & PL & 5 & 4 & 8 \\
\hline$\overline{\mathbf{P S}}$ & 3 & 4 & 6 & $\mathbf{P S}$ & 6 & 7 & 9 \\
\hline$\overline{\mathbf{Z E}}$ & 0 & $\overline{\mathbf{0}}$ & $\overline{\mathbf{0}}$ & $\overline{Z E}$ & 0 & 0 & $\overline{0}$ \\
\hline $\mathbf{N S}$ & 18 & $\overline{0}$ & 15 & NS & 18 & $\mathbf{0}$ & 15 \\
\hline NL & 17 & 13 & 14 & NL & 2 & 16 & 17 \\
\hline \multicolumn{4}{|c|}{$\boldsymbol{\theta} 3$} & \multicolumn{4}{|c|}{$\theta 4$} \\
\hline $\mathrm{E}_{\Gamma}$ & $\overline{\mathbf{P}}$ & $\overline{\mathbf{Z}}$ & $\overline{\mathbf{N}}$ & $\mathbf{E}_{\boldsymbol{\Gamma}}$ & $\mathbf{P}$ & $\mathbf{Z}$ & $\mathbf{N}$ \\
\hline PL & 8 & 7 & 11 & PL & 8 & 7 & 11 \\
\hline$\overline{\mathbf{P S}}$ & 6 & 7 & 9 & $\overline{\mathbf{P S}}$ & 9 & 10 & 12 \\
\hline$\overline{\mathbf{Z E}}$ & 0 & $\overline{0}$ & 0 & $\overline{\mathbf{Z E}}$ & 0 & 0 & 0 \\
\hline NS & 3 & $\mathbf{0}$ & 18 & $\mathbf{N S}$ & 3 & $\mathbf{0}$ & 18 \\
\hline NL & 2 & 16 & 17 & NL & 15 & 1 & 2 \\
\hline \multicolumn{4}{|c|}{$\theta 5$} & \multicolumn{4}{|c|}{$\theta 6$} \\
\hline $\mathbf{E}_{\boldsymbol{\Gamma}}$ & $\overline{\mathbf{P}}$ & $\mathbf{Z}$ & $\mathbf{N}$ & 1 & $\overline{\mathbf{P}}$ & $\mathbf{Z}$ & $\mathbf{N}$ \\
\hline$\overline{\mathbf{P L}}$ & 11 & 10 & 14 & $\overline{\mathbf{P L}}$ & 11 & 10 & 14 \\
\hline $\mathbf{P S}$ & 9 & 10 & 12 & $\mathbf{P S}$ & 12 & 13 & 15 \\
\hline$\overline{\mathbf{Z E}}$ & 0 & $\overline{\mathbf{0}}$ & 0 & $\overline{\mathbf{Z E}}$ & 0 & 0 & 0 \\
\hline NS & 6 & $\mathbf{0}$ & 3 & $\mathrm{NS}$ & 6 & $\mathbf{0}$ & 3 \\
\hline NL & 5 & 1 & 2 & $\mathbf{N L}$ & 8 & 4 & 5 \\
\hline \multicolumn{4}{|c|}{$\theta 7$} & \multicolumn{4}{|c|}{$\theta 8$} \\
\hline $\mathbf{E}_{\Gamma}$ & $\overline{\mathbf{P}}$ & $\bar{Z}$ & $\overline{\mathbf{N}}$ & $\bar{\Gamma}$ & $\mathbf{P}$ & $\bar{Z}$ & $\overline{\mathbf{N}}$ \\
\hline$\overline{\mathbf{P L}}$ & 14 & 13 & 17 & \begin{tabular}{|l}
$\mathbf{P L}$ \\
\end{tabular} & 14 & 13 & 17 \\
\hline PS & 12 & 13 & 15 & \begin{tabular}{|l|}
$\mathbf{P S}$ \\
\end{tabular} & 15 & 16 & 18 \\
\hline$\overline{Z E}$ & 0 & $\overline{0}$ & $\mathbf{0}$ & $\mathbf{Z E}$ & $\mathbf{0}$ & $\mathbf{0}$ & $\mathbf{0}$ \\
\hline $\mathbf{N S}$ & 9 & $\overline{0}$ & 6 & \begin{tabular}{|l}
$\mathbf{N S}$ \\
\end{tabular} & 9 & 0 & 6 \\
\hline NL & 8 & 4 & 5 & \begin{tabular}{|l|} 
NL \\
\end{tabular} & 11 & 7 & 8 \\
\hline \multicolumn{4}{|c|}{$\theta 9$} & \multicolumn{4}{|c|}{$\theta 10$} \\
\hline $\mathbf{E}_{\Gamma}$ & $\overline{\mathbf{P}}$ & $\mathbf{Z}$ & $\mathbf{N}$ & $\mathbf{E}_{\boldsymbol{\Gamma}}$ & $\overline{\mathbf{P}}$ & $\mathbf{Z}$ & $\mathbf{N}$ \\
\hline PL & 17 & 16 & 2 & PL & 17 & 16 & 2 \\
\hline$\overline{\mathbf{P S}}$ & 15 & $\overline{16}$ & 18 & $\overline{\mathbf{P S}}$ & $\overline{18}$ & 1 & 3 \\
\hline$\overline{\mathbf{Z E}}$ & 0 & $\overline{0}$ & $\mathbf{0}$ & $\mathbf{Z E}$ & 0 & 0 & 0 \\
\hline NS & 12 & 0 & 9 & $\mathbf{N S}$ & 12 & 0 & 9 \\
\hline NL & 11 & 7 & 8 & NL & $\overline{14}$ & 10 & 11 \\
\hline \multicolumn{4}{|c|}{$\theta 11$} & \multicolumn{4}{|c|}{$\theta 12$} \\
\hline $\mathbf{E}_{\boldsymbol{\Gamma}}$ & $\overline{\mathbf{P}}$ & $\overline{\mathbf{Z}}$ & $\mathbf{N}$ & $\mathbf{E}_{\Gamma}$ & $\overline{\mathbf{P}}$ & $\mathbf{Z}$ & $\mathbf{N}$ \\
\hline$\overline{\text { PL }}$ & 2 & 1 & 5 & PL & 2 & 1 & 5 \\
\hline$\overline{\mathbf{P S}}$ & 18 & $\overline{1}$ & $\overline{3}$ & $\overline{\mathbf{P S}}$ & 3 & 4 & 6 \\
\hline$\overline{\mathbf{Z E}}$ & 0 & $\overline{0}$ & $\overline{0}$ & $\overline{\mathbf{Z E}}$ & 0 & 0 & 0 \\
\hline NS & 15 & 0 & 12 & $\mathbf{N S}$ & 15 & 0 & 12 \\
\hline $\mathbf{N L}$ & 14 & 10 & 11 & $\mathbf{N L}$ & 17 & 13 & 14 \\
\hline
\end{tabular}

There is a total of 180 rules, the control rule is described and developed using Mamdani's minimum operation rule $\mathrm{e}^{[9]}$.

$\mu_{\mathrm{Ni}}^{\prime}(\mathrm{n})=\min \left(\alpha_{\mathrm{i}}, \mu_{N i}(n)\right)$

$\alpha_{i}=\min \left(\mu_{A \mathrm{i}}\left(E_{\varphi}\right), \mu_{B \mathrm{i}}\left(E_{\Gamma}\right), \mu_{C \mathrm{i}}\left(\theta_{s}\right)\right)$

Where $\mu_{\mathrm{A}}, \mu_{\mathrm{B}}, \mu_{\mathrm{C}}$ and $\mu_{\mathrm{N}}$ are membership function of sets $\mathrm{A}, \mathrm{B}, \mathrm{C}$ and $\mathrm{N}$ of the variables $\mathrm{E}_{\varphi}, \mathrm{E}_{\Gamma}, \theta$ and $\mathrm{n}$ respectively. Thus the member function $\mu \mathrm{N}$ of the output $\mathrm{n}$ (i.e., the Nth rule) is point wise given by:

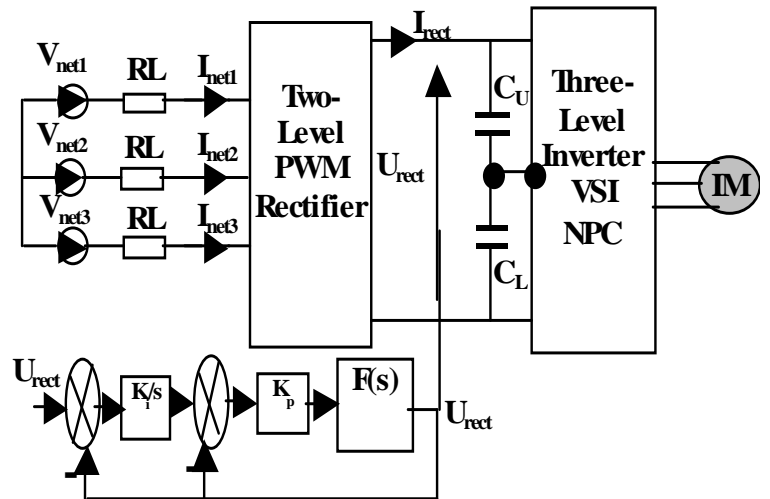

Fig. 6: Two level PWM rectifier, feedback linear control, filter, three level inverter VSI NPC, induction motor

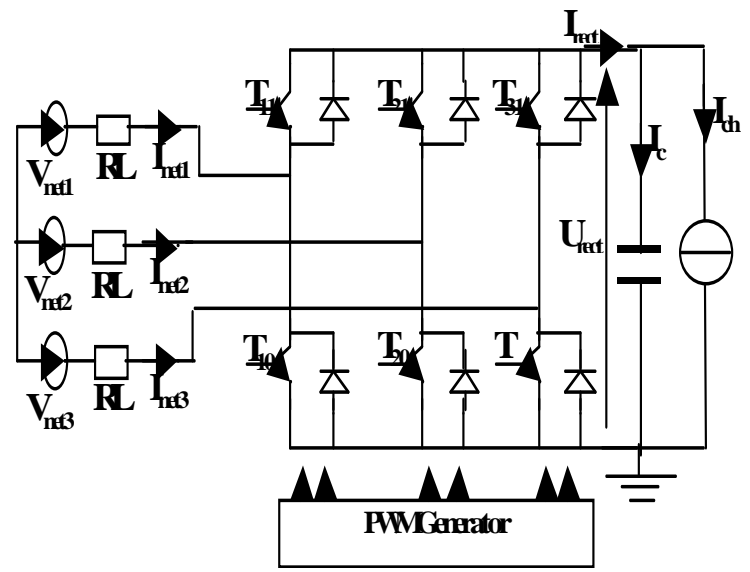

Fig. 7: Two-level current rectifier structure

$\mu_{\mathrm{Ni}}(\mathrm{n})=\max _{i=1}^{180}\left(\mu_{N i}^{\prime}(n)\right)$

The maximum criterion method is used for defuzzification, the outputs are crisp in this case because the flux and torque control by vector voltage has in nature a desecrate behavior.

$\mu_{\text {Nout }}(\mathrm{n})=\max _{N=1}^{19}\left(\mu_{N}(n)\right)$

The fuzzy output which has the maximum possibility distribution, is used as control output. Then output $=$ Nout .

Performances of the two-level current rectifierthree-level voltage inverter-induction motor cascade: We study the complete cascade composed by the induction machine fed by three-level inverter VSINPC controlled by FDTC strategy and two-level PWM current rectifier. In addition to solve the problem of the instability of the output DC voltages of the rectifier, we introduce in the cascade a feedback control using IP regulator, Fig. 6. 


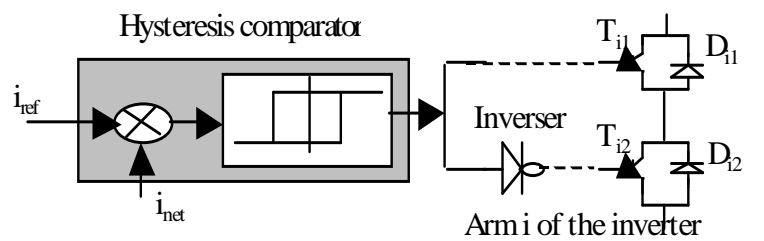

Fig. 8: Principle of the hyteresis control

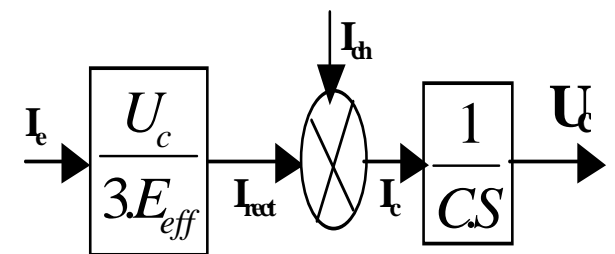

Fig. 9: Voltage Control loop model of two-level rectifier

Three- phases two-level current rectifier: The reversibility of the rectifier source inverter allows it to work as current rectifier, Fig. 7. The complementary law for this converter is:

$B_{11}=\bar{B}_{10}, B_{21}=\bar{B}_{20}, B_{31}=\bar{B}_{30}$

With $\mathrm{i}=1,2$ and 3 . follow:

A knowledge model of this rectifier is defined as

$\mathrm{V}_{\mathrm{km}}=\mathrm{F}_{\mathrm{i}} \cdot \mathrm{U}_{\text {rect }}$

$\left[\begin{array}{l}V_{a} \\ V_{b} \\ V_{c}\end{array}\right]=\frac{1}{3}\left[\begin{array}{ccc}2 & -1 & -1 \\ -1 & 2 & -1 \\ -1 & -1 & 2\end{array}\right]\left[\begin{array}{l}F_{1} \\ F_{2} \\ F_{3}\end{array}\right] U_{r e c t}$

Where $\mathrm{V}_{\mathrm{a}}, \mathrm{V}_{\mathrm{b}}$ and $\mathrm{V}_{\mathrm{c}}$ : are the input voltages of twolevel PWM rectifier.

The output current of the rectifier expressed with switching function, with the value " 1 " when the switch is set to the positive voltage or " 0 " when the switch is set to negative voltage and input currents, is given as flows :

$\mathrm{I}_{\text {rect }}=\mathrm{F}_{1} \cdot \mathrm{i}_{\text {net } 1}+\mathrm{F}_{2} \cdot \mathrm{i}_{\text {net } 2}+\mathrm{F}_{3} \cdot \mathrm{i}_{\text {rnet } 3}$

We use the current hysteresis strategy to control this rectifier. Fig. 8 shows the principle of this method.

The reference currents are defined by following expression:

$I_{r e f i}=I_{m} \cdot \sin \left(\omega t-\frac{2 \pi}{3}(i-1)\right)$

We design with $\varepsilon_{\mathrm{i}}$ the difference between reference current and reel current $\mathrm{I}_{\text {net }},\left(\varepsilon_{i}=i_{\text {refi }}-i_{\text {neti }}\right)$. The strategy algorithm is given as follow:

$$
\begin{aligned}
& F_{i}^{k+1}=0 \text { If } I_{n e t i} \geq I_{r e f i}+h \\
& F_{i}^{k+1}=1 \text { If } I_{\text {neti }} \leq I_{\text {refi }}-h
\end{aligned}
$$

$F_{i}^{k+1}=F_{i}^{k}$ If $I_{r e f i}-h<I_{n e t i}<I_{r e f i}+h$

Where $F_{i}^{k}:$ Value of $\mathrm{F}_{\mathrm{i}}$ at $\mathrm{K}^{\text {th }}$ iteration

$F_{i}^{k+1}:$ Value de $\mathrm{F}_{\mathrm{i}}$ at $\mathrm{K}+1^{\text {th }}$ iteration $\mathrm{h}$ : hysteresis band width

Voltage control loop model: To improve the input voltages of the three-level NPC inverter, we propose to use a linear control loop with IP regulator to maintain equal the different input DC voltages of the inverter Fig. 9.

The modelling of this loop is based on the principle of conservation of the instantaneous power with the rectifier's hypothesis without losses; this loop imposes the currents of network reference.

- Input power:

$p_{i}=\sum_{k=1}^{k=3}\left(V_{n e t k} \cdot I_{n e t k}-R \cdot I_{n e t k}^{2}-\frac{L}{2} \frac{d I_{n e t k}^{2}}{d t}\right)$

- Output power:

$\mathrm{P}_{\mathrm{o}}=\mathrm{U}_{\mathrm{c}} \cdot \mathrm{I}_{\mathrm{rect}}=\mathrm{U}_{\mathrm{c}} \cdot\left(\mathrm{I}_{\mathrm{c}}+\mathrm{I}_{\mathrm{ch}}\right)$

Using the principle of instantaneous power conservation and by neglecting the Joule's losses in the resistance, we can write:

$\sum_{k=1}^{k=3}\left(V_{n e t k} \cdot I_{n e t k}=\frac{L}{2} \frac{d I_{n e t k}^{2}}{d t}+U_{c} \cdot I_{r e c t}\right)$

While supposing the currents of the network sinusoidal and in phase with their voltages, we can write then:

3. $\mathrm{E}_{\mathrm{eff}} \cdot 1_{\mathrm{e}}=\mathrm{U}_{\mathrm{c}} \cdot \mathrm{I}_{\mathrm{rect}}$

With: $\left\{\begin{array}{l}V_{\text {netk }}=\sqrt{2} E_{e f f} \cdot \sin \left(\omega s-\frac{2 \pi}{3}(k-1)\right. \\ I_{\text {netk }}=\sqrt{2} \cdot I_{e} \sin \left(\omega i-\frac{2 \pi}{3}(k-1)\right.\end{array}\right.$

$\mathrm{K}$ : arm number of rectifier $(\mathrm{k}=1,2,3)$.

The model of the voltage loop of the three-phase two-level rectifier deduced from the relation (V.29) is given like follows:

We use a regulating IP (Integral Proportional) for the voltage loop, in which the general principle of the enslavement of the continuous voltages to the input of the three-phase three-level inverter is given below, Fig. 10 .

\section{THE SIMULATION RESULTS}

The validity of the proposed DTC algorithm for three-level voltage source inverter is proved by the simulation results. The parameters of motors are given in the Appendix. The used flux and torque contraints 


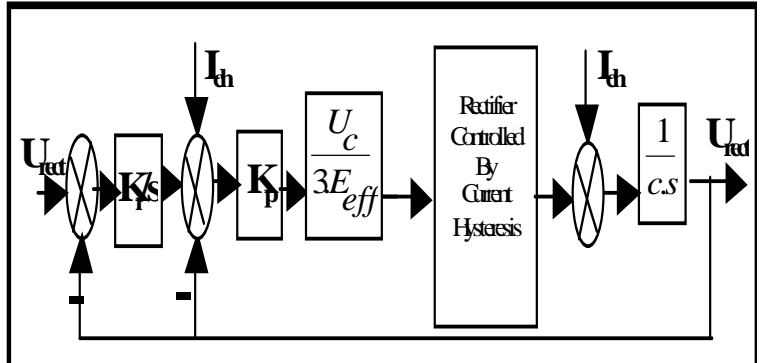

Fig. 10: Feedback linear control of the output voltage of the two-level rectifier
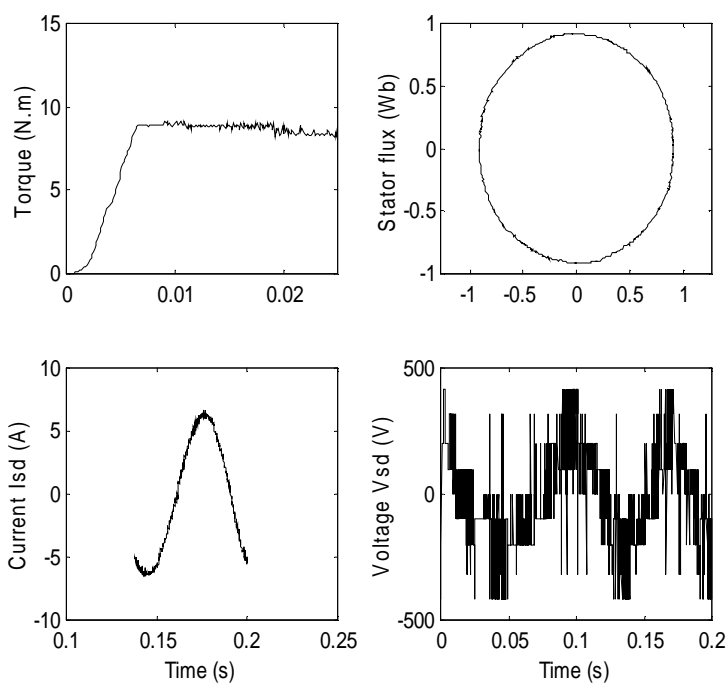

Fig. 11: Vector flux locus, torque step response, current $\mathrm{I}_{\mathrm{sd}}$, voltage $\mathrm{V}_{\mathrm{sd}}$

for the FDTC approach are expressed in percent with respect to th flux and torque reference values.

$\mathrm{E}_{\varphi \max }=3 \%, \mathrm{E}_{\varphi \min }=-3 \%, \mathrm{E}_{\Gamma \min 1}=-0.8 \%$,

$\mathrm{E}_{\Gamma \min 2}=-3 \%, \mathrm{E}_{\Gamma \max 1}=0.8 \%, \mathrm{E}_{\Gamma \max 2}=3 \%$.

The simulation results illustrate both the steady state and the transient performance of the proposed torque control scheme. In the first part, we assume that FDTC system is supplied by a battery of voltage $V_{d}$. Fig. 11 shows the phase current and flux for steady state and transient operation at 9 N.m with $0.9 \mathrm{~Wb}$ when the input voltages are assumed constants $\left(\mathrm{U}_{\mathrm{c} 1}=\mathrm{U}_{\mathrm{c} 2}=\mathrm{V}_{\mathrm{d} / 2}\right)$. The wave form of the stator current is closed to a sinusoidal signal and the voltage $\mathrm{V}_{\mathrm{sd}}$ is well distributed, probabilistic voltage harmonic analysis has been proposed in $^{[10]}$.

The trajectory of the flux is nearly a circle and answers more quickly, (7ms). Figure12 (b) shows that the output torque reaches the new reference torque in about $2 \mathrm{~ms}$, fast torque response is obtained and a constant flux maintained during the torque reverse (a)
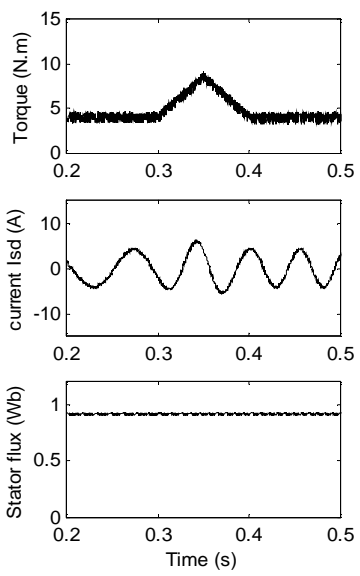

(b)
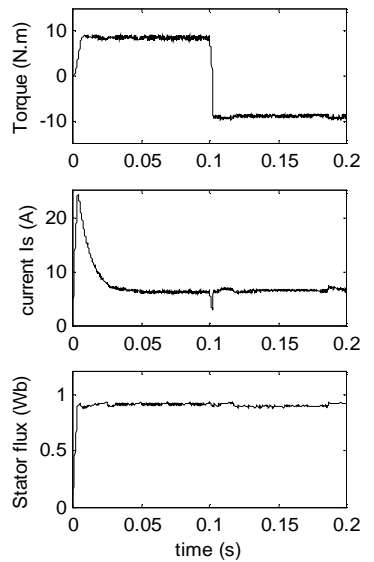

Fig. 12: (a) Torque response with the reference value of torque is variable by ramp from 4.5 to $9 \mathrm{Nm}$. (b) Torque reverse response from 9 to $-9 \mathrm{Nm}$

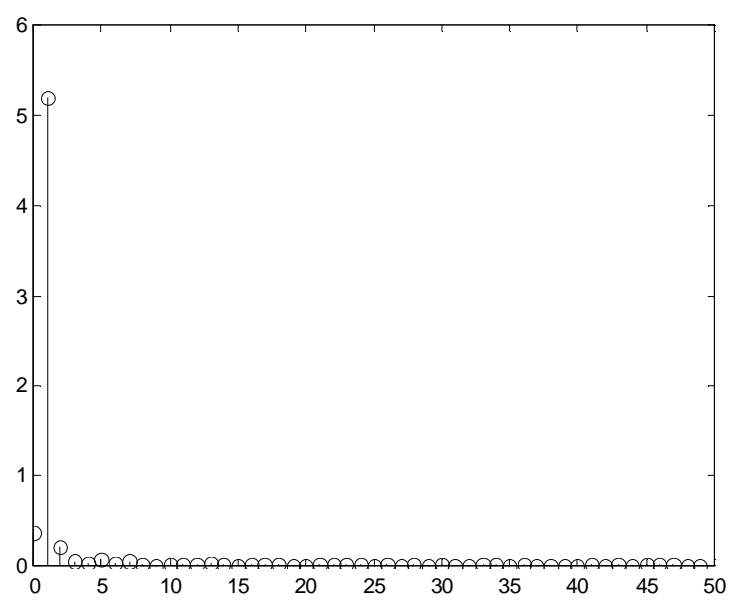

Fig. 13: Line current harmonics $I_{\text {sal }}$

response from +9 N.m to -9 N.m and flux command at $0.9 \mathrm{~Wb}$. and a well response is achieved in the other hand with a ramp reference Fig. 12 (a).

The FFT of the current waveform of phase (a) is shown in Fig. 13. The phase currents generated by the three-level inverter have low harmonic contents with FDTC system (5\% THD).

In the second part, we simulate the performances of the FDTC scheme associated to its supply for nominal references of the flux and torque without feedback control. The two-level rectifier is controlled by hysteresis technique with a band equal to $\mathrm{h}=0.5 \mathrm{~A}$, the reference input currents with nominal values at a frequency of $50 \mathrm{~Hz}$, the parameters of the intermediate capacitors filter are: $\mathrm{C}_{\mathrm{U}}=\mathrm{C}_{\mathrm{L}}=10 \mathrm{mF}$, the input 
Am. J. Appl. Sci., 4 (7): 417-425, 2007
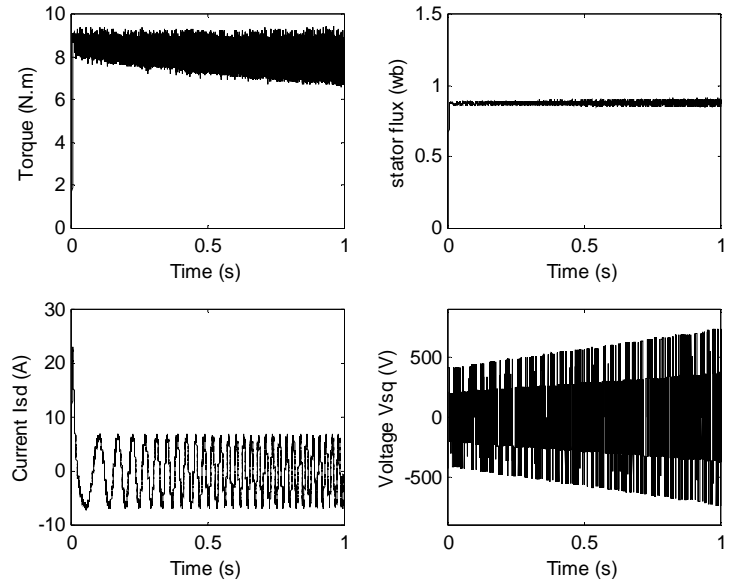

Fig. 14: The performances of the DTC drive associated to its supply with nominal references of the flux and torque
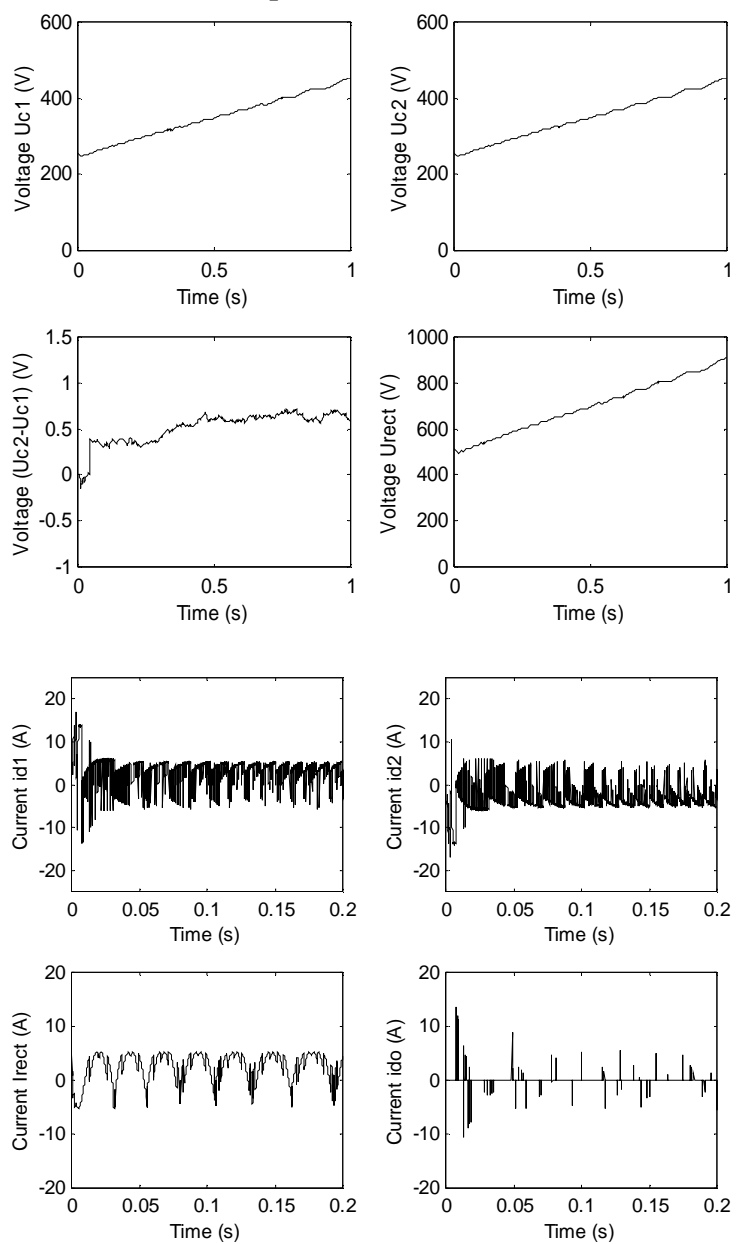

Fig. 16: Input currents of a three-level voltage source inverter and the output current of the rectifier $\left(\mathrm{I}_{\mathrm{d} 1}, \mathrm{I}_{\mathrm{d} 2}, \mathrm{I}_{\mathrm{d} 0}, \mathrm{I}_{\mathrm{drect}}\right)$
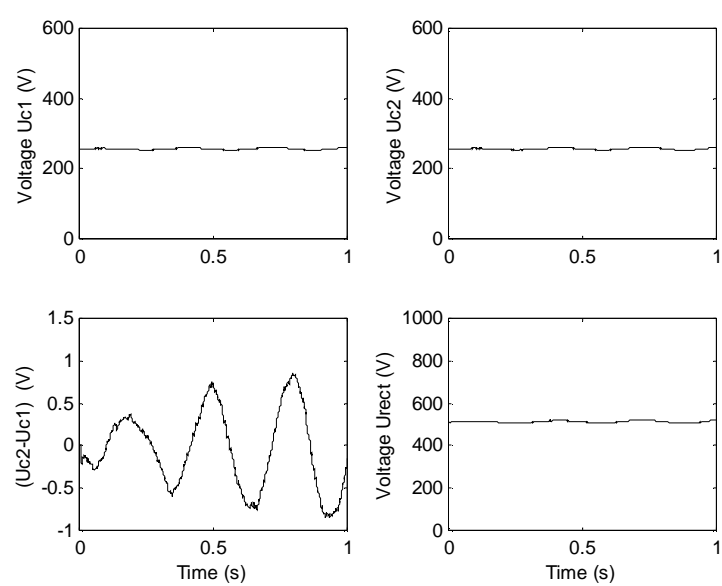

Fig. 17: DC output voltage of the rectifier Urect, intermediate voltage filters $\mathrm{U}_{\mathrm{c} 1}, \mathrm{U}_{\mathrm{c} 2}$ and their difference $\left(\mathrm{U}_{\mathrm{c} 2}-\mathrm{U}_{\mathrm{c} 1}\right)$
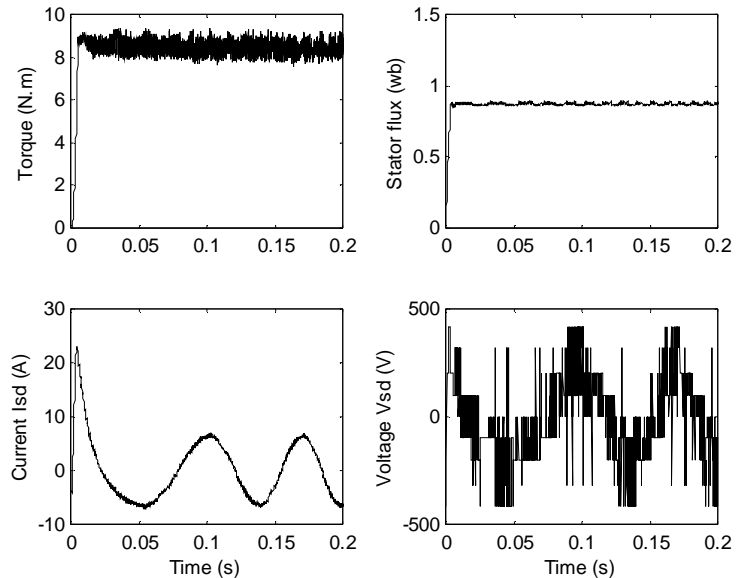

Fig. 18: The performances of the DTC drive associated to its supply at nominal references of the flux and torque with Feedback linear control

voltages of the inverter are initialized to $\mathrm{Uc} 1=\mathrm{Uc} 2=$ $257 \mathrm{~V}$.

Fig. 14 shows that the magnitude of the voltage $\mathrm{V}_{\mathrm{sd}}$ increases gradually with the increase in the voltages of the intermediate filters $\left(\mathrm{U}_{\mathrm{c} 1}, \mathrm{U}_{\mathrm{c} 2}\right)$. Consequently, the performances of control are degraded and the semiconductors are subjected to a commutation with high voltage; what produces a failure of control, an increase in the losses due to commutation and breakdown of the semiconductors. In addition, the electromagnetic torque and stator flux oscillate around their nominal values (9 N.m and $0.9 \mathrm{~Wb}$ ) without notable overtaking but with an important harmonic content. 
It is noted in Fig. 15, that the input voltages of the three-level inverter are increasing and their difference is about $0.7 \mathrm{~V}$. This difference can reach the value of $10 \mathrm{~V}$ in the case of the FOC control and then FDTC system has self-compensation by adequate selection of the vector voltages. The input currents of the three-level inverter $I_{d 1}$ and $I_{d 2}$ have the same shape, but reversed one compared to the other, the $\mathrm{I}_{\mathrm{d} 0}$ current has practically zero value, Fig. 16. Fig. 17 and 18 present the simulation results of the DC middle point voltage evolution and the performance of the DTC scheme when a feedback control is introduced in the cascade. The parameters of the IP regulator are: $\mathrm{K}_{\mathrm{i}}=700$, $\mathrm{K}_{\mathrm{P}=0.01}$. The input voltages of the inverter are initialized to $\mathrm{U}_{\mathrm{cl}}=\mathrm{U}_{\mathrm{cl}}=257 \mathrm{~V}$ with $\mathrm{C}_{\mathrm{U}}=\mathrm{C}_{\mathrm{L}}=10 \mathrm{mF}$.

We note that: the difference of the input voltages of the rectifier decreases considerably, output voltages of the rectifier and intermediate filter voltages $\left(\mathrm{U}_{\mathrm{c} 1}, \mathrm{U}_{\mathrm{c} 2}\right)$ are balanced. The progression of the magnitude of the output voltage of three-level inverter $\left(\mathrm{V}_{\mathrm{sd}}\right)$ is clearly attenuated. Thus, the performances of FDTC control are highly improved with complete cascade. The electromagnetic torque and stator flux are then controlled at their nominal values with low ripple.

\section{CONCLUSION}

The direct torque control FDTC was introduced to give a fast and good dynamic torque and can be considered as an alternative to the field oriented control FOC technique. It is concluded that the proposed control produces better results for transient and the steady state operation then the conventional control.

In this study, a DTC systems using three-level GTO voltage source inverter was presented it is suitable for high-power and high-voltage applications. We enhance the DTC approach by introducing fuzzy logic controller. From the analysis of these results establish the following remarks:

* The fuzzy logic approach has a fast torque and flux response as compared to the conventional DTC.

* The stator current wave form is more close to the suitable sinusoidal signal.

* Introducing a feedback linear control to solve the usual problem of unbalanced voltages input in three-level VSI.NPC can easily control the neutral point voltage. From this analysis high dynamic performance, good stability and precision are achieved; the results obtained are full of promise to use this system in high voltage and great power applications as electrical traction.
Appendix A: Induction motors parameters: Rated power : $1.5 \mathrm{~kW}$; Rated voltage : $220 \mathrm{~V}$; Rated speed : $1420 \mathrm{rpm}$;Rated frequency : $50 \mathrm{~Hz}$;Rated current : 3.64 A (Y) et $6.31(\Delta)$;Stator resistance : $4.85 \Omega$;Rotor resistance : $3.805 \Omega$; Stator inductance : $0.274 \mathrm{H}$;Rotor inductance : $0.274 \mathrm{H} ;$ Magnetizing Inductance : 0.258 $\mathrm{H}$;Number of poles : 4 ; Rotor inertia : 0.031 Kg.m ${ }^{2}$;Friction Coefficient : 0.008 N.m.s $/ \mathrm{rd} ; \mathrm{Vdc}=$ $514 \mathrm{~V} ; \mathrm{Te}=100 \mu \mathrm{s}$.

\section{REFERENCES}

1. Lee, Y.H., B.S. Suh and D.S. Hyan, 1996. A novel PWM scheme for a three-level voltage source inverter with GTO thyristors. IEEE Trans. on Ind. Appl., 33: 260-268.

2. Takahashi, I. and T. Noguchi, 1986. A new quickresponse and high-efficiency control strategy of an induction motor. IEEE Trans. on IA, 22: 820-827.

3. Trounce, J.C., S.D. Round and R.M. Duke, 2001. Comparison by simulation of three-level induction motor torque control schemes for electrical vehicle applications. Proc. Intl Power Eng. Conf., 1: 294299.

4. Xuezh, W.U. and L. Huang, 2001. Direct torque control of three-level inverter using neural networks as switching vector selector. IEEE IAS, Annual Meeting, 30 Sep-04 Oct., 2001.

5. Bacha, F., A. Sbai and R. Dhifaui, 1998. Tow approaches for direct torque control of an induction motor. CESA Symposium on Control, 1: 562-568.

6. Casadei, D., G. Grandi, G. Serra and A. Tani, 1994. Switching strategies in direct torque control of induction machines. ICEM, 2: 204-209.

7. Zaimeddine, R. and E.M. Berkouk, 2004. A Novel DTC scheme for a three-level voltage source inverter with GTO thyristors. SPEEDAM 2004, Symposium on power electronics, electrical drives, automation \& Motion, June, 16-18, 2: F1A-9-F1A12.

8. Zaimeddine, R. and E.M. Berkouk, 2005. A Novel DTC scheme for a five-level voltage source inverter with GTO thyristors. SSD 2005, Third IEEE Intl. Conf. on Systems, Signal \& Devices, March, 21-24, pp: 91.

9. Mir, S.A., M.E. Elbuluk and D.S Zinger, 1994. fuzzy implementation of direct self control of induction machines. IEEE Trans. on IA, 30: 729735.

10. Kaboli, S., E. Vahdati-Khajeh and M.R. Zolghadri, 2006. Probabilistic voltage harmonic analysis of direct torque controlled induction motor drives. Power Electronics, IEEE Trans., 21: 1041-1052. 